\title{
Asthma diagnosis and treatment - 1014. Single center experience of 4 cases of diffuse panbronchiolitis clinically presented as treatment resistant ashtma
}

\author{
Kyung Hee Park, Jae-Hyun Lee, Chein-Soo Hong, Jung-Won Park
}

From 2nd WAO International Scientific Conference (WISC 2012)

Hyderabad, India. 6-9 December 2012

\section{Background}

Diffuse panbronchiolitis (DPB) is a severe form of bronchiolitis affects the whole lung fields. Although its etiology is unknown, it can be well treated by macrolide administration. The incidence of DPB is high among Asian, especially Japanese and Korean. We experienced 4 DPB patients misdiagnosed to severe asthma or combined with asthma.

\section{Case 1}

A 70-year old female came to our clinic complaining uncontrolled asthma for 10 years. Spirometry showed obstructive lesion (FEV1=94.9\%, FEV1/FVC $=71.08 \%$ ) with $5 \%$ bronchodilator (BD) response. PC20 of methacholine was $3.8 \mathrm{mg} / \mathrm{ml}$. Chest CT showed diffuse bronchial wall thickening with tree in bud sign. Treated with clarithromycin for 1 month, $\mathrm{FEV}_{1}$ was improved from $64.9 \%$ to $84.2 \%$ without asthma medication.

\section{Case 2}

A 52-year old male complained his uncontrolled asthma for 4 years. He was diagnosed as severe asthma and treated at other hospital. His FEV1 was $1.74 \mathrm{~L}$ (54.4\%) and improved $20.6 \%$ after bronchodilator. CT scan showed diffuse bronchiolitis thus we adminster clarithromycin for 6 months. $\mathrm{FEV}_{1}$ was improved from $54.4 \%$ to $95.3 \%$. He could discontinue inhaledcorticosteroid and other asthma medications.

\section{Case 3}

A 25-year old male with uncontrolled asthma. Initial FEV1 was $2.51 \mathrm{~L}(62.6 \%)$ and severe sputum eosinophilia. His CT scan shows diffuse bronchitis with tree bud sign and then treated with clarithromycin for 9 months. $\mathrm{FEV}_{1}$ was improved from $62.6 \%$ to $88.4 \%$. He reduced daily amount of inhaled corticosteroid.

\section{Case 4}

A 60-year old female was visited to our clinic with severe asthma. Spirometry showed obstructive lesion (FEV1 = $42.9 \%, \mathrm{FEV} 1 / \mathrm{FVC}=73.37 \%$ ) without $\mathrm{BD}$ response. $\mathrm{CT}$ scan shows diffuse bronchial wall thickening. $\mathrm{FEV}_{1}$ was improved from $42.9 \%$ to $97.1 \%$ after 6 months use of clarithromycin without any asthma medication.

\section{Conclusion}

We report 4 cases of DPB were mistaken for severe asthma or combined with asthma. We suggested DPB must be considered as a differential diagnosis for treatment resistant asthmatics in Korea.

Published: 23 April 2013

doi:10.1186/1939-4551-6-S1-P14

Cite this article as: Park et al:: Asthma diagnosis and treatment - 1014. Single center experience of 4 cases of diffuse panbronchiolitis clinically presented as treatment resistant ashtma. World Allergy Organization Journal 2013 6(Suppl 1):P14 